\title{
TED Talks as a Listening Resource in the EFL College Classroom
}

\author{
Prof. Reima Al-Jarf \\ King Saud University, Riyadh, Saudi Arabia \\ reima.al.jarf@gmail.com \\ ORCID ID: 0000-0002-6255-1305
}

DOI: http://doi.org/ 10.36892/ijlls.v3i3.691

\begin{tabular}{|c|c|}
\hline $\begin{array}{l}\text { Received: } \\
\text { 02/09/2021 }\end{array}$ & $\begin{array}{l}\text { Abstract } \\
\text { The article proposes a model for integrating TED Talks (TTS) in EFL college }\end{array}$ \\
\hline & $\begin{array}{l}\text { listening practice. It shows instructors where TTs can be located, gives } \\
\text { reasons for using TTs, criteria for selecting TTs, the listening skills that can } \\
\text { be developed, and an instructional strategy. TTs provide a variety of real-life } \\
\text { themes, speakers, motivation, and inspiration. They save instructors' time and }\end{array}$ \\
\hline $\begin{array}{l}\text { Keywords: } \\
\text { TED Talks, listening } \\
\text { skills, listening } \\
\text { comprehension, } \\
\text { intensive listening, } \\
\text { extensive listening. }\end{array}$ & $\begin{array}{l}\text { effort as they are available on You Tube, mobile apps or in the TED website. } \\
\text { In selecting TTs, the instructor should take into consideration the students' } \\
\text { interests, difficulty level of the TT language and content, its length in minutes, } \\
\text { and speed and accent of the speaker. Before watching a TT, she posts the title } \\
\text { of the TT on an LMS or social media platform. She sets goals for listening and } \\
\text { gives pre-questions to help the students comprehend the TT content. The } \\
\text { students view the TTs on their smart phones in the classroom or at home; } \\
\text { individually, in pair, or small groups; synchronously or asynchronously. } \\
\text { While listening, the students take notes, and answer the questions. After } \\
\text { listening, they discuss their answers. The instructor serves as a facilitator. She } \\
\text { gives feedback, encouragement, and help with difficulties. Further } \\
\text { recommendations for enhancing EFL college students' listening skills and for } \\
\text { extending the use of TTs to interpreting courses are given. }\end{array}$ \\
\hline
\end{tabular}

\section{INTRODUCTION}

$\mathrm{TED}^{1}$ is an acronym derived from the first letters of Technology, Entertainment, and Design. It is a non-profit organization, started by Richard Saul Wurman in 1984, devoted to spreading ideas, in the form of short, powerful talks that are 18 minutes or shorter. The TED Talk (TT) videos are based on presentations given at the main TED conference or any of the many TED events around the world. The TTs cover all kinds of topics: Technology, design, science, business, collaboration, innovation, social change, health, nature, the environment, the future, communication, activism, child development, personal growth, humanity, society, identity, and community in more than 100 languages. As of June 2011, TTs' combined viewing reached 500 million. In November 2012, TTs had been watched a billion times worldwide. In January 2018, over 2,600 TTs were freely available. In 2021, there are 3700+ TTs which include 547 talks on global issues, 780 talks on science, in addition to podcasts, and daily Talks on Spotify. The TED website contains the TED Conferences, TED Translators, TED Community, TED Institute, TED Books, TED Blog, Library of TTs, and the Audacious Project.

\section{LITERATURE REVIEW}

Due to the popularity of TTs in all languages and all countries, they have been used as an instructional resource and have also been the subject of research in many areas of specialty

\footnotetext{
${ }^{1}$ https://www.ted.com/about/our-organization
} 
including language teaching and learning. For example, in social work, Loya and Klemm (2016) recommended the use of TTs as a resource and teaching tool for educators. Both educators and students found the TTs useful in social work education, because the TT videos bring world-renowned speakers into the classroom, encourage discussions in the social work classroom, provide social work educators with rich teaching opportunities and references to specific Council on Social Work Education competencies and practice behaviors.

A similar study was conducted with engineering students in which García-Pinar (2019) used authentic TTs that focus on technology and engineering. They used text-based instruction in designing an ESP course for engineering students based on relevant, varied, and engaging tasks to enhance authentic language use by the students. The students gave oral presentations and analyzed the distinct discourse and linguistic features that are specific to the spoken genre of technological and engineering TTs. Results showed that the TTs helped develop new and thought-provoking ideas that are interesting and meaningful for the students and that are related to different engineering sub-specialties. The TTs turned the classroom environment into a more engaging place, generated through the performance of meaningful tasks. The oral presentations served as activities that resembled the real world and future workplace for engineering students and promoted students' instrumental motivation.

In a physical chemistry course, Stout (2020) utilized an oral presentation assignment which was reimagined as a TT. The presentation was part of a larger course project that included consideration of what traits mark good writing and good speaking that students can engage in. Results of the project indicated that this new format resulted in improved presentations, enhanced student engagement and deeper learning.

In addition, the literature review showed numerous studies that focused on using TTs in developing a variety of language and translation skills such as vocabulary (Hsu, 2020; Nurmukhamedov, 2017; Nguyen and Boers, 2019); reading comprehension skills (Allagui, 2021; Bianchi and Marenzi, 2016); writing and summarization skills (Howard, 2017; Hashimoto, Fukuda and Okazaki, 2015); English for academic purposes (Leopold, 2016); pragmatic skills such as co-speech gestures and move analysis (Masi, 2020; Ratanakul, 2017); discourse analysis such as macro discourse markers (Uicheng and Crabtree 2018); and translation skills (Comas-Quinn and Fuertes Gutiérrez, 2019).

Specifically, TTs have been important for developing students' speaking skills. Numerous studies have investigated the role TTs in enhancing students' public speaking skills. For example, in Columbia, Martínez Hernández, Vargas Cuevas and Ramírez Valencia (2018) used TTs to develop students' public speaking skills and to support English learning autonomously through blogs, applications, and online courses. TED videos provided the students with communicative skills that helped them express their ideas in English. Authentic TED videos and subtitles encouraged the students to learn English for oral communication.

In China, Li, Gao and Zhang (2016) adopted TED videos as a learning material in an English Public Speaking Course to encourage the students to be better speakers. The findings showed that the students responded very positively to this new type of instruction and were satisfied with the improvement they made in their English language skills. They became creators rather than just learners. Their critical listening and thinking skills greatly improved.

Moreover, TTs were used with engineering students who have difficulty in class participation, comprehending subject lectures or communicating with their teachers and peers in English. The students were given pre- and post-viewing activities and were continuously assessed using classroom observation and language production activities in the classroom. The findings demonstrated that use of TTs as a resource in the classroom improved engineering students' English language speaking ability and encouraged them to use the language confidently. TTs made students' learning more engaging and enhanced their experience of learning English (Karunakar, 2019).

Furthermore, TTs were used as an ICT tool to improve oral presentation skills, vocabulary retention, hard cognitive skills and reduce speaking anxiety level in business 
students. The research findings revealed that business students' oral presentation skills and vocabulary retention levels improved. Students in the experimental group were more motivated, and enthusiastic to give oral presentations and became more confident, and free of anxiety and tension (Salem, 2019).

Regarding studies that integrate TTs in second language listening instruction, they are very limited compared to those that focus on speaking. A study by Mirzaei, Meshgi and Kawahara (2016) utilized an Automatic Speech Recognition system to identify second language (L2) students' listening problems. TED transcripts of videos generated by the Automatic Speech Recognition software often revealed recognition errors, which may indicate difficult video segments for L2 listeners. L2 students watched and transcribed short segments of TED videos. The researchers found that minimal pairs, homophones, negative structures, and boundary recognition challenging for L2 listeners. The results also revealed that errors in students' transcriptions significantly increased when they transcribed segments of an audio in which the Automatic Speech Recognition system made errors. This means that the Automatic Speech Recognition errors can be used as a predictor of L2 students' difficulties in listening to a particular audio.

To develop L2 students' listening skills, Schmidt (2016) employed a listening journal, i.e., a book in which the students recorded their extensive and intensive listening practices, and reflections on their listening experiences. In extensive listening, the students chose and listened to texts that appealed to them from a source provided by their instructor. The listening resource presented was a web-based tool that provided activities for student learning and practice. The students were also required to reflect on their successes, strengths, and weaknesses in order to identify the skills they needed to improve. Strengthening the weaker skills became a goal that the students needed to focus on during further listening practice in the classroom, outside the classroom, and in subsequent listening journals.

\section{AIMS OF STUDY}

Schmidt (2016) asserted that most second language learners have never been taught how to listen in the foreign language. The students need to learn how to listen, focus on sounds, words, and building meaning from the bottom up and the top down and need to practice extensive and intensive listening.

Secondly, a number of studies conducted by Al-Jarf (2019); Al-Jarf (2018) and AlJarf (2005), with samples of students enrolled in listening and interpreting courses, at the College of Languages and translation, King Saud University, Riyadh, Saudi Arabia showed that the students have listening comprehension problems such as (a) understanding main ideas and details in a lecture; (b) connecting ideas and information in the spoken discourse with their background knowledge; (c) inferring the meaning of difficult words from the spoken context; (d) recognizing the organizational structure of oral discourse and identifying signaling devices such as first, second, third for enumeration; because, consequently, as, since for cause-effect relationships; however, on the contrary, although, yet, similarly, likewise for comparison and contrast; before, after, since then, during, followed by, preceding for chronological order; in front, between, below, above, beside for special order and so on. They also have auditory discrimination/identification (phonological) problems such as: (i) failing to hear or discriminate vowel or consonant phonemes in the word; (ii) failing to hear the final syllable or suffix; (iii) failing to distinguish homophones; (iv) failing to recognize flaps and elision; (v) failing to hear the correct word sequence; (vi) failing to hear word boundary, pause and juncture; (vii) inability to recognize and relate word and sentence stress to part of speech and meaning; (viii) distinguishing and understanding American vs British pronunciation; and (ix) identifying parts of speech from word endings and word order.

Thirdly, the literature review showed lack of studies in Saudi Arabia that use TTs in developing EFL college students' English language and translation and/or interpreting skills, in general, and listening skills, in particular. Therefore, this study proposes a model for 
integrating TTs in listening practice as a supplement to in-class instruction that depends on the textbook. Specifically, it aims to show EFL college instructors: (i) why use TTs; (ii) where TTs can be located; (iii) criteria for selecting TTs; (iv) listening skills that can be developed with TTs; (v) an instructional strategy with TTs; and (vi) instructor's role.

\section{MATERIALS, TASKS AND PROCEDURES}

\subsection{Why Use TTs}

Martínez Hernández, Vargas Cuevas and Ramírez Valencia (2018) indicated that TED is a website and downloadable application where videos in which students can see a wide variety of English speakers from many parts of the world, speaking with the audience in a fun and familiar manner, about various topics of interest, with cultural content, which expand ways of referring to the same topic. Rubenstein (2012) also asserted that TTs provide relevant content that informs teachers of best practices, current issues, and innovative future possibilities, and promote their understanding of instructional practices and student motivation.

In addition, TTs are significant as a resource in the EFL listening classroom. Prior studies reported above show that use of TT with EFL students proved to be effective in enhancing students' learning. TTs have further advantages: They are free. They provide a variety of themes, speakers, and English accents. They have different difficulty levels, lengths, and speeds. They can be viewed on a smart TV in the classroom, on the laptop, tablet or mobile phone out of class. They can be viewed anywhere, anytime and as many times as the students need. TTs bring listening courses alive and allow EFL students to use their visual and auditory senses to learn new concepts, unfamiliar ideas, and information that is inspiring and motivating. They save the instructors' time and effort as they are available online and instructors do not have to prepare any lecture videos, or supplementary listening material. Instructors can share the TTs that sthey find useful with colleagues the same listening courses.

\subsection{Locating and Selecting TTs}

The instructor can search for TTs on the TED website. There is an alphabetical list of topics under numerous topic categories. The instructor can locate TTs from the TED mobile and tablet Apps, from Smart TV Apps, YouTube, and Smart speaker apps by entering a specific topic or a category of interest to the students (See Images $1 \& 2$ in the Appendix).

The TT chosen should depend on the students' interests, degree of familiarity, difficulty level and complexity of the TT language and content. The instructor should pay attention to the TT length in minutes. She may watch several TTs and pay attention to the speed and accent of the speaker, content details and language difficulty level. The TT's difficulty level should match the students' proficiency level. Students may start with short lectures, with slower speech and familiar topics and move on to longer lecture and less familiar topics. Several TTs on the same topic can be assigned to the students each week to accommodate the different ability levels in the group and how fast the students work. Students can suggest TTs of interest to them. Examples of TTs are shown is Image (3) in the Appendix.

\subsection{Listening Skills Practised with TT's}

According to Al-Jarf (2021d), Al-Jarf (2019), and Al-Jarf (2018), listening skills include the following:

1) Auditory identification and discrimination of spoken sounds in connected speech such as:

- homophones: cite, site, sight.

- words with variant pronunciations: often, schedule. 
- words with two pronunciations depending on the part of speech and/or meaning: abuse, separate, present, minute, tear.

- words commonly confused: affect/effect; accept/except; compliment/complement; principle/principal; alter/altar.

- words with two parts of speech and two different stress patterns: present, export, accent, conduct, convict, digest, perfect, permit, suspect, transport.

- words with suffixes that change stress: Photograph, photography, photographic) and words with suffixes that do not change stress (develop, development; terminate, termination.

- sentence stress.

- rising-falling intonation and rising intonation.

- assimilation, i.e., changes in phonemes such as voicing and devoicing, due to the influence of adjacent sounds as in newspaper, education, graduate, hit you, I have to go, I used to, bless you, don't you, did you, please you, walked, washed, pleased, released.

- flaps as in butter letter, Water, total, Kettle, cattle, Little, settle, hit her, latter \& ladder, bitter \& bit her.

- elision and reduction as in background, raspberry, fifth, months, handsome, depends, kindness, accidents, lends, winds, bunch, lunch, fields, builds, fields, revenge, strange, some of the best, I asked her.

- contractions such as I'm, he's, we're, they're, they'll, won't, we'd, haven't, can't, about'er, about'im, about'em, give'm, for'em, for'er, tell'em, tell'er, let'im, le'me, ask'er, ask'im, ov'im, ov'em, ov'er, ov'is mother, he'd better, I'd rather, could'ev, wanna, gonna, I don't know.

- pause, juncture and vowel linkage as in every one, everyone; some times, sometimes; all ways, always; all together, altogether; an accident; an organization; tonight's a problem; beat it; sort'em out; that's a great idea.

- differences in American and British pronunciation as in pronouncing vowels (box, top, past, demand, mandatory, laboratory); pronunciation of $/ \mathrm{r} /$; deletion of $/ \mathrm{r} /$; use of clear and dark /l/; deletion of $/ \mathrm{t} /$ when preceded by an $/ \mathrm{n} /$ and followed by a vowel as in interactive, internet, interrupt, international; use of flaps in matter, sitter, butter, letter, little, kettle, total; pronouncing /t/ as a glottal stop in beaten, kitten, fatten, sentence) and others.

1) Listening (auditory) comprehension of ideas and information that are explicitly or implicitly stated in the spoken lectures such as:

- Literal comprehension of main ideas, supporting details, cause-effect relationships, comparisons and contrasts, sequence of events, chronological order, and character traits in a lecture.

- Inferential comprehension such as inferring supporting details, sequence, cause and effect relationships, comparisons, character traits, figurative language and predicting outcomes.

- Evaluation, i.e., judgments of fact or opinion, reality or fantasy, acceptability, worth, appropriateness, adequacy or validity, desirability, and judgement of the language and style used, and the effects of the oral lecture in the light of some criteria specified by the instructor.

- Appreciation, i.e., emotional responses to the content, sensitivity to various literary genres, identification with characters and incidents, reaction to the author's use of language, and response to generated images in the oral lecture.

- Deriving meaning of unfamiliar words from: (i) contextual clues in the lecture (topic, commonly used expressions, idioms, colloquialisms, figures of speech, 
proverbs, and other familiar sayings); (ii) structural/syntactic clues in the lecture (the position of a word in a sentence; recognizing sentence patterns, and identifying and understanding passive, emphatic and exclamatory structures); (iii) morphological clues in the lecture (derivatives, inflectional endings, and comparatives, contractions, and possessives).

- Connecting words with their antecedents in spoken discourse.

- Recognizing types of text organization (chronology, enumeration, classification, analogy, cause-effect, compare/ contrast, whole-part, process), organization clues and transitional words).

- Connecting information in the lecture with the student's prior knowledge in the content area of the lecture, current global events, historical events, geographical area, scientific information, and others.

- Making predictions from the lecture title, keywords in the lecture, signaling devices and/or examples.

- Visualizing, i.e., forming a mental picture of ideas, information, events...etc. in the talk.

1) Identification of pragmatic purposes such as informing, demanding, requesting, giving background information, giving directions and instructions, making an announcement, using verbal and nonverbal signals, warning, drawing attention to something, relating information, guiding, and directing, stating rules, labelling objects, people, places, stating a problem and others.

2) Stylistic analysis such as using a command, imperative mode, passive structures, emphasis, embedded and complex sentences, using simple vocabulary and forms to suit the audience and the function of the TT.

3) Note-taking skills such as: (i) Use of shorthand and abbreviations (lb., Prof., $\mathrm{Dr}, \mathrm{Mr}$, P.O. Sun, Aug. a.m., c.m. Eng. Am, ft, bldg, ch, vs, rm, adj, corp., ltd, sing, dept, pop, stat, min, max, gov., comp, sp); (ii) focusing on content words, figures, dates, statistics, examples; (iii) making an outline of the main topics and sub-topics in the lecture.

\subsection{Instructional Procedures with TTs}

The instructor can use Blackboard, Zoom, Microsoft Teams, WebEx, Google Meet, Facebook, Twitter, Instagram, or Telegram for posting titles of TTs to be listened to, the tasks to be performed, students' responses to the tasks and teacher's feedback and comments.

Before listening to a TT, the instructor introduced the TT under study, sets goals for listening to the TT, and tells the students what they need to do and focus on. She gives some vocabulary overview and pre-questions about the main ideas and supporting details in the lecture to help the students understand the TT content. The pre-questions may require the students to give the meaning of some difficult words from the spoken context, pay attention to some grammatical structures, pronunciation of some words, compounds and phrases, the purpose of the TT, its pragmatic use, stylistic features, and cultural issues related to the lecture.

The students can watch the assigned TT individually, in pairs or in small groups. They can watch it in class (face to face), online synchronously or asynchronously at home. They can also watch the TT on their smart phone, laptop, tablet, or smart TV. While listening to a TT, the students can take notes, jot down some terminology or examples, pay attention to the structure of the information as to whether it is classifications, enumeration, cause-effect, comparisons-contrasts, chronology, whole-part, analogy, or narrative. They pay attention to specific vocabulary and grammatical structures. They answer listening comprehension questions about: (i) the main ideas and supporting details; (ii) organizational clues that denote 
descriptions, classifications, definitions, processes, whole-part and cause-effects relationships and so on; (iii) derive the meanings of difficult words from the spoken context. They may also use their background knowledge to infer the meaning of difficult words and meaning of the whole TT. They can outline the content of the TT, i.e., the main ideas and important details. At an advanced stage, they can identify the stylistic, pragmatic, and sociolinguistic features of English TTs, evaluate TTs and reflect on them.

After listening to a TT, the students summarize, retell, or paraphrase the content orally or in writing. Tables, flow charts, diagrams, photos, and mind maps can be used to show the TT information details and relations. They discuss their answers with each other and with their instructor. They can discuss answers to questions individually, in pairs or small groups. They discuss difficulties in vocabulary and grammatical structures. In addition, the students practice pronouncing unfamiliar words, breaking terms down into prefix, root, and suffix. They practice stress, intonation, pause and juncture. Answers and summaries can be posted on Blackboard, Facebook, Twitter, Telegram or any other LMS or social media platform. Live discussions can be held via the Facebook Watch Party or the Live tool, Zoom or Microsoft Teams platforms.

\subsection{Instructor's Role}

The instructor serves as a facilitator. S(he) should support inquiries, discuss students' difficulties. S(he) encourages and models the listening skills that the students need to practice. The students should be required and encouraged to engage and participate in, respond to and be actively involved in the listening activities. The instructor can give extra credit for participation and for completing the listening tasks and can include excerpt of a TT on tests.

During all instructional phases, the students should not be left on to work on their own. They should not watch a TT passively without having to perform a task specified by the instructor. The instructor gives feedback. She encourages the students to interact, engage in and have an active role in the discussion. The students comment on each other's performance. The instructor can assign more TTs that provide practice with the aspects that are difficult for the students.

\section{RECOMIMENDATIONS AND CONCLUSION}

The current study proposed the integration of TTs in teaching listening to Saudi students majoring in English and translation at language, literature, and translation departments. Listening instructors can exploit latest technologies to help their students develop their intensive and extensive listening skills. However, they should always keep in mind that technology does not teach by itself, and its use does not guarantee the automatic learning of the content of lectures or development of listening skills. The students' active role and the instructor's guidance are crucial in facilitating the use of TTs to improve students' listening skills. The instructor can encourage the students to keep the TTs they have listened to in a portfolio or a folder on their mobile.

To save time, instructors and students can create a repository of selected TTs which they find suitable and useful for their listening courses. A special Facebook or Twitter page may serve as a TT repository that can be updated by the students and supervised by the instructor, with comments on their lexical, grammatical, pragmatic, and stylistic aspects added by the students. Such a TT repository would serve as a pedagogical resource for other students who wish to improve their English with authentic short real-life lectures as an inclass or out of class extension activity.

To develop EFL students' intensive and extensive listening skills, the author recommends further activities that can be used as a supplement to in-class instruction that depends on the textbook such as: 
- Using social media, live streaming apps and videoconferencing software such as Periscope and Elluminate for class discussions and student-student and studentinstructor interaction (Al-Jarf, 2021c; Al-Jarf, 2013).

- Using mobile pronunciation apps, daily English lessons apps, podcasts and general listening apps such as www.talkenglish.com, and apps for practicing auditory comprehension skills (Al-Jarf, 2012; Al-Jarf, 2020a).

- Listening to mobile audiobooks followed by activities such as giving a summary of the audiobook content or answering questions on it (Al-Jarf, 2021d). Listening to children's short stories and samples of children's literature that are easy and interesting for the freshman students, in particular (Al-Jarf, 2015; Al-Jarf, 2016).

- Analyzing aspects of the public speaking and communication skills of the TT speakers they have listened to such as: (i) Non-verbal communication: Posture, gestures, face and eye, voice; (ii) how the topic was developed; turn talks and shifting from one point to another; (iii) organization of ideas and information (Al-Jarf, 2007).

- The instructor can give communicative feedback that focuses on meaning and highlight errors related to rules or skills under study in a particular session. The instructor gives feedback on the presence and location of errors but should not give the correct forms. She should encourage self-correction and peer-correction of errors (Al-Jarf, 2021a).

- Using social media as Facebook, Telegram, WhatsApp, Twitter, or Instagram for oral and written communication between the instructors and their students especially in the distance learning environment during the Coronavirus Pandemic (Al-Jarf, 2020b).

Finally, the integration of TTs in simultaneous or consecutive interpreting practice by students taking interpreting courses using multimedia language labs is open for further investigation by future research (Al-Jarf, 2021b).

\section{REFERENCES}

Al-Jarf, R. (2005). The relationship among spelling, listening, and decoding skills in EFL freshman students. Journal of the English Language Teachers in Korea (ETAK), 1(2), $35-55$.

Al-Jarf, R. (2007). From reticence to fluency: The effect of TBLT on students' speaking ability. The International Conference on Task-Based Language Teaching. Centre for Language and Migration, University of Leuven, Belgium.

Al-Jarf, R. (2012). Mobile technology and student autonomy in oral skill acquisition. In Javier E. Díaz Vera's Left to My Own Devices: Learner Autonomy and MobileAssisted Language Learning, Innovation and Leadership in English Language Teaching, Vol. 6, 105-129. Emerald Group Publishing Ltd. Retrieved from https://doi.org/10.1163/9781780526478_007

Al-Jarf, R. (2013). Integrating Elluminate webconferences in EFL grammar instruction. $2^{\text {nd }}$ International Conference on Technologies of Information and Communications in Education and Training (TICET 2013). 60-76. ERIC Number: ED610560.

Al-Jarf, R. (2015). Enhancing reading and speaking skills in EFL through multicultural children's short stories. 7th International Conference titled Building Cultural Bridges (ICBCB), Almaty, Kazakhstan. April 23-24, 2015. ERIC Document ED610158.

Al-Jarf, R. (2016). Enhancing reading and speaking skills in EFL through multicultural literature. Asian Academic Research Journal of Social Sciences \& Humanities (AARJSH), 3(7), 288-298. 
Al-Jarf, R. (2018). Effect of background knowledge on auditory comprehension in interpreting courses. In Renata Jančaříková (ED.) Interpretation of Meaning Across Discourses, 2nd Edition, pp. 97-108. Czech Republic, Brno: Muni Press.

Al-Jarf, R. (2019). EFL freshman students' difficulties with phoneme-grapheme relationships. 5th VietTESOL International Convention. University of Foreign Languages, Hue City, Vietnam. October 11-12, 2019.

Al-Jarf, R. (2020a). Mobile apps in the EFL college classroom. Journal for Research Scholars and Professionals of English Language Teaching (JRSP-ELT), 4(22),1-5.

Al-Jarf, R. (2020b). Communication among instructors and students via Twitter. In Irena Vassileva, Mariya Chankova, Esther Breuer and Klaus P. Schneider (Eds.) The Digital Scholar: Academic Communication in Multimedia Environment, 265-280. Berlin: Frank \& Timme GmbH.

Al-Jarf, R. (2021a). A model for communicative error correction in Saudi EFL freshman students' writing. i-manager's Journal on English Language Teaching, 11(2), 32-41. Retrieved from https://doi.org/10.26634/jelt.11.2.17719

Al-Jarf, R. (2021b). Feasibility of digital multimedia language labs for interpreting instruction as perceived by interpreting instructors in Saudi Arabia. International Journal of Linguistics, Literature and Translation (IJLLT), 4(4), 70-79. http://dx.doi.org/10.32996/ijllt.2021.4.4.8

Al-Jarf, R. (2021c). Issues in using Periscope for live academic lectures during the Covid-19 pandemic. i-manager's Journal of Educational Technology, 18(1), 15-25. Retrieved from https://doi.org/10.26634/jet.18.1.17711

Al-Jarf, R. (2021d). Mobile audiobooks, listening comprehension and EFL college students. International Journal of Research -GRANTHAALAYAH, 9(4), 410-423. Retrieved from https://doi.org/10.29121/granthaalayah.v9.i4.2021.3868

Allagui, B. (2021). TED talk comments to enhance critical thinking skills in an undergraduate reading and writing course. Education and Information Technologies, 26(3), 29412960.

Bianchi, F. \& Marenzi, I. (2016). Investigating student choices in performing higher-level comprehension tasks using TED. 23rd EUROCALL Conference, Limassol, Cyprus. Aug 24-27, 2016. ERIC Number: ED572020.

Comas-Quinn, A. \& Fuertes Gutiérrez, M. (2019). Working with online communities: translating TED talks. Research-publishing.net. ERIC Number: ED596845.

García-Pinar, A. (2019). Getting closer to authenticity in the course of technical English: Task-Based Instruction and TED talks. English Language Teaching, 12(11), 10-22.

Hashimoto, S., Fukuda, E. \& Okazaki, H. (2015). Improving summarizing skills with TED talks: An account of a teaching lesson using explicit instruction. 22nd EUROCALL Conference, Padova, Italy, Aug 26-29, 2015. ERIC Number: ED564220.

Hayward, P. (2017). Incorporating TED talk assignments into a public-speaking course. Communication Teacher, 31(4), 239-244.

Hsu, W. (2020). Can TT transcripts serve as extensive reading material for mid-frequency vocabulary learning? TEFLIN Journal: A publication on the teaching and learning of English, 31(2), 181-203. 
Howard, S. (2017). Ideas worth spreading: TED's rhetorical position in college composition. CEA Forum, 46(2) Sum-Fall, 62-87.

Karunakar, M. T. (2019). Encouraging English language production using TED talks at the tertiary level: a study in a technical college. Teaching English with Technology, 19(4), 57-68.

Leopold, L. (2016). Honing EAP learners' public speaking skills by analyzing TED talks. TESL Canada Journal, 33(2), 46-58.

Li, Y., Gao, Y. \& Zhang, D. (2016). To speak like a TED speaker--a case study of TED motivated English public speaking study in EFL teaching. Higher Education Studies, 6(1), 53-59.

Loya, M. \& Klemm, T. (2016). Teaching note--using TED talks in the social work classroom: encouraging student engagement and discourse. Journal of Social Work Education, 52(4), 518-523.

Martínez Hernández, M., Vargas Cuevas, A. \& Ramírez Valencia, A. (2018). TED talks as an ICT tool to promote communicative skills in EFL students. English Language Teaching, 11(12), 106-115.

Masi, S. (2020). Exploring meaning-making practices via co-speech gestures in TED talks. Journal of Visual Literacy, 39(3-4), 201-219.

Mirzaei, M., Meshgi, K. \& Kawahara, T. (2016). Leveraging automatic speech recognition errors to detect challenging speech segments in TED talks. $23^{\text {rd }}$ EUROCALL Conference, Limassol, Cyprus, Aug 24-27, 2016. ERIC Number: ED572207.

Nguyen, C. \& Boers, F. (2019). The effect of content retelling on vocabulary uptake from a TED talk. TESOL Quarterly: A Journal for Teachers of English to Speakers of Other Languages and of Standard English as a Second Dialect, 53(1), 5-29.

Nurmukhamedov, U. (2017). Lexical coverage of TED talks: implications for vocabulary instruction. TESOL Journal, 8(4), 768-790.

Ratanakul, S. (2017). A study of problem-solution discourse: examining TED talks through the lens of move analysis. LEARN Journal: Language Education and Acquisition Research Network, 10(2), 25-46.

Rubenstein, L. (2012). Using TED talks to inspire thoughtful practice. Teacher Educator, 47(4), 261-267.

Salem, A. (2019). A Sage on a stage, to express and impress: TED talks for improving oral presentation skills, vocabulary retention and its impact on reducing speaking anxiety in ESP settings. English Language Teaching, 12(6), 146-160.

Schmidt, A. (2016). Listening journals for extensive and intensive listening practice. English Teaching Forum, 54(2), 2-11.

Stout, R. (2020). Reimagining an oral presentation assignment as a TED talk improves student oral presentations, leading to more significant learning. Journal of Chemical Education, 97(1), 271-274.

Uicheng, K. \& Crabtree, M. (2018). Macro discourse markers in TED talks: how ideas are signalled to listeners. PASAA: Journal of Language Teaching and Learning in Thailand, 55(Jan-Jun), 1-31. 
APPENDIX

Image (1): A to Z List of TED Topics

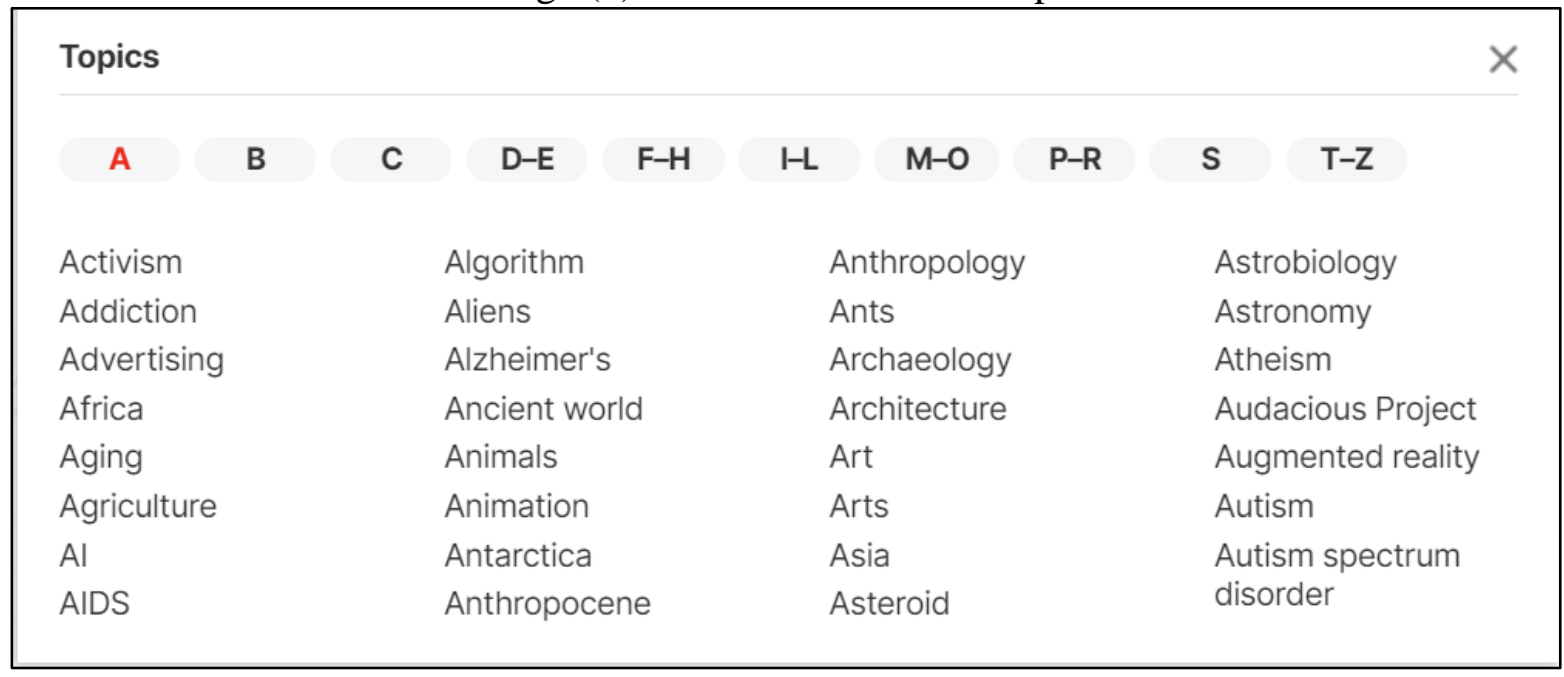

Source: https://www.ted.com/talks?sort=newest\&duration=0-6

Image (2): Where TED Talks Can Be Located

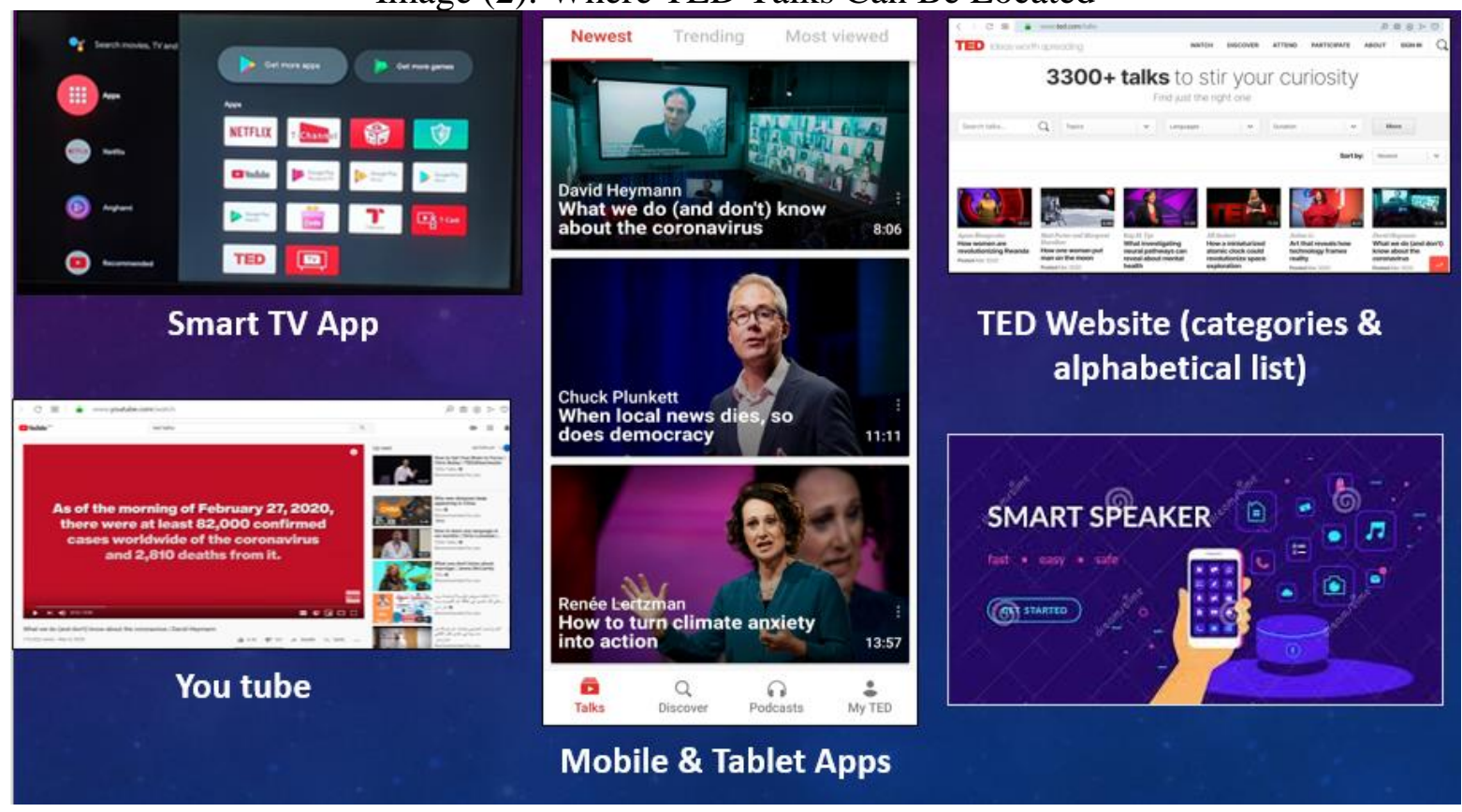


TED Talks as a Listening Resource in the EFL College Classroom

Image (3): Examples of TED Talks That Can Be Used in Freshman Listening Practice

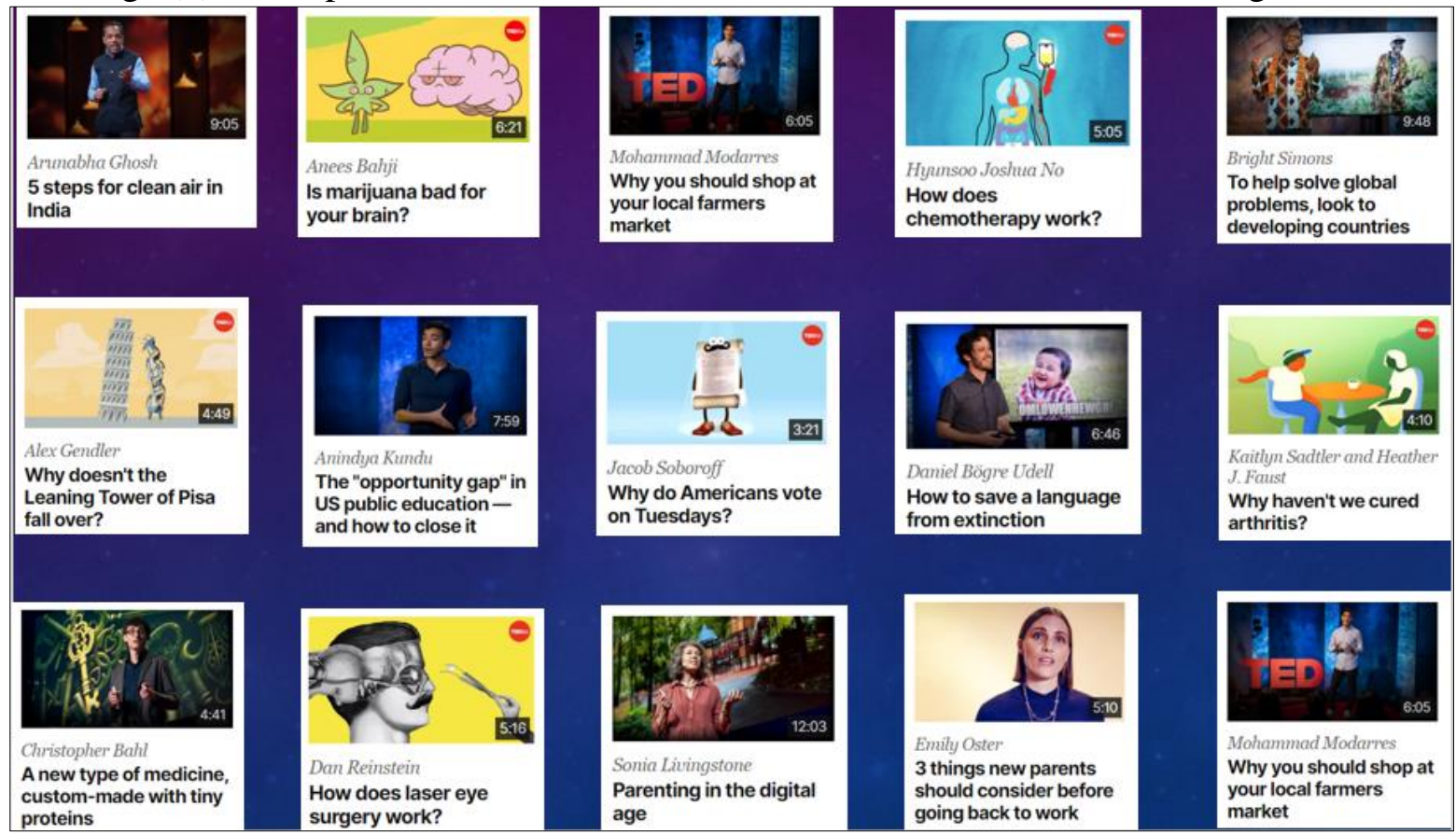

